\title{
A case report on attempted suicide by hanging of an adolescent girl
}

\author{
Shakya KN', Bhatta $A^{2}$, Bhandari B ${ }^{3}$ \\ ${ }^{1}$ Kashyap Narsingh Shakya, Professor; ${ }^{2}$ Anwesh Bhatta, Lecturer; ${ }^{3}$ Bikash Bhandari, Second year MD Resident; Department \\ of Pediatrics, Kathmandu Medical College, Sinamngal, Kathamandu, Nepal
}

\begin{abstract}
Suicidal attempt by hanging is a growing problem during adolescence. Globally, $8.5 \%$ of all deaths among young people is accounted for by suicide. It is preventable, provided the risk factors and pre-suicidal behavior are identified for averting such a tragic happening. Pediatricians have crucial role to play in this.
\end{abstract}

Key words: Adolescent, Attempted suicide, Hanging, Preventable

\section{INTRODUCTION}

$\mathrm{H}$ anging is a preventable cause of morbidity and mortality. There may be several risk factors associated with it ${ }^{1}$, which if identified in time may prevent such unfortunate happenings.

Suicide accounts for $8.5 \%$ of all deaths among young people (15-29 years of age) globally ${ }^{2}$, and in Nepal too, it is not an uncommon occurrence.

Despite a dearth of literature on suicide in adolescents in Nepal, pediatricians are not unfamiliar with off and on cases of attempted suicide by hanging or self poisoning coming for their care. Their role in the prevention of suicide has long been established ${ }^{3}$. They can help prevent adolescent suicide by knowing the symptoms of depression and other pre-suicidal behavior ${ }^{4}$.

We report here a case of attempted suicide by hanging in an adolescent girl with a typical history and pathognomonic sign of ligature mark in the neck.

\section{CASE}

A 12 year old girl child from Sindhupalchowk district, Nepal was brought to the emergency room with lethargic and altered consciousness state. It was alleged that she was incidentally found by her grandfather in a thin forest nearby their home. She was found with her

Address for correspondence

Prof. K. N. Shakya

Professor, Department of Pediatrics,

Kathmandu Medical College, Sinamngal, Kathamandu, Nepal

E-mail: shakyakashyap@yahoo.com neck wrapped around by a long cloth piece with other end tied to the branch of a tree. Her arms were free with feet touching the ground; suggestive of partial hanging. She was immediately rescued by her grandfather, who unfastened the noose of clothing around her neck and rushed her to the hospital emergency room, where she was resuscitated. According to the grandfather, the girl was admonished by her mother for a trivial reason on the preceding day and had become very depressed since then.

Two months back, she had similarly attempted to hang herself with an intension to end her own life but was prevented from doing so by her grandfather who was familiar with her behavior and intentions.

On examination, at presentation in the $E R$, the girl was lethargic but conscious and replying to questions. A bluish ligature mark was present obliquely at the front of neck, directed upwards and backwards on both sides. The surrounding surface appeared hemorrhagic. (as shown in figure 1) Her vitals were stable with normal oxygen saturation in room air by pulse oxymetry. Emergency CT scan of the neck and head performed was reported normal without any cervical bony fracture or deformity as confirmed by consultation with orthopaedic and neurosurgery team. The girl was admitted to the ward and kept under monitoring in the pediatric high care unit for observation. Meanwhile, psychiatric consultation was obtained. On day three of observation, she was transferred to the psychiatric ward where she received counseling and psychotherapy prior to discharge. 


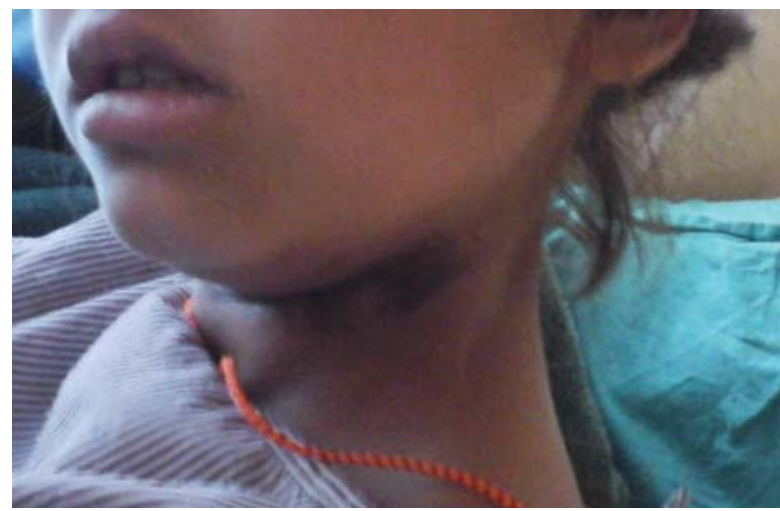

Figure 1: Ecchymotic V-mark of noose in the neck

\section{DISCUSSION}

Statistics about suicide in children in the developing countries is scarce. However, in the Western world, suicide is a leading cause of death in children and adolescents ${ }^{5}$. It is a rare phenomenon in pre-adolescents, such that, in the age group between 5-14 years, it is reported as 0.5 per 100000 for females and of 0.9 per 100000 for males ${ }^{5}$. During adolescence however, it features as a prime issue and the rates of suicide and suicide-related behaviors increase with increasing age $\mathrm{e}^{5,6}$. The sex incidence is variable, too. Although, the rates of suicide are higher in boys, the rates of suicidal ideation and suicide attempt show female preponderance ${ }^{7}$.

Another important aspect of the happening is the method chosen for suicide. It is influenced by the availability of the means used for the suicide. In the United States, firearms have been described as the leading suicide method among youth, followed by hanging/suffocation, and self-poisoning ${ }^{8}$. In a report of 10-year retrospective review, hanging (48\%) was found to be the most common method of suicide, followed by firearms $(13 \%)$, poisoning $(10 \%)$, drowning $(10 \%)$, and blunt force vehicular trauma $(10 \%)^{9}$. In the EU countries also, the pattern seen has been consistent with the most prevalent methods of suicide chosen by children and adolescents $<19$ years of age, which are hanging, jumping from heights and railway-suicides (both genders), intoxication (females) and firearms (males) ${ }^{10}$.
Suicidal Behavior Disorder is a proposed DSM-5 (Diagnostic and Statistical Manual of Mental Disorders, fifth edition) diagnosis which would be assigned to individuals who have made a suicide attempt within the past two years. A suicide attempt is defined, as a self-destructive act deliberately carried out where there is a clear expectation of death ${ }^{11}$. Suicide by hanging is considered a simple suicide method that does not require complicated techniques. The materials required are easily available, and a wide range of ligatures can be used. Therefore, it is considered a difficult method to prevent ${ }^{12}$. In the International Statistical Classification of Diseases and Related Health Problems, suicides by hanging are classified under the code X70: Intentional self-harm by hanging, strangulation, and suffocation ${ }^{13}$.

According to a published large series, patients who survived hospital admission had favorable outcome ${ }^{14}$. The overall mortality in the series was $9.5 \%$ and the prognosis was favorable, even with patients who arrived with a Glasgow Coma Scale (GCS 8). The overall survival was $90 \%$ and only $3.5 \%$ were discharged with severe or permanent disability ${ }^{14}$. Psychosocial problems and stresses, such as conflicts with parents, breakup of a relationship, school difficulties or failure, legal difficulties, social isolation, and physical ailments (including hypochondriacal preoccupation), were commonly observed in young people who attempted suicide $^{3}$. Knowledge of these and other psychiatric, social, cultural, and environmental risk factors for suicidal behavior facilitate identification of youths at highest risk $^{15}$. The potential contribution of pediatrician in this respect has been acknowledged along with important recommendations. ${ }^{4}$

\section{CONCLUSION}

Hanging is a common mode of suicide in adolescents and youths. It is Pediatrician's role of identifying and preventing the risk factors associated with pre suicidal behaviours. Prevention of risk factors and identification of pre-suicidal behavior can forestall such unfortunate happenings.

\section{REFERENCES}

1. Brent DA. Risk factors for adolescent suicide and suicidal behavior: mental and substance abuse disorders, family environmental factors, and life stress. Suicide Life Threat Behav. 1995;25 Suppl:52-63.
2. Laido Z, Voracek M, Till B, Pietschnig J, Eisenwort $B$, Dervic K, et al. Epidemiology of suicide among children and adolescents in Austria, 2001-2014. Wien Klin Wochenschr. 2017; 129(3): 121-28.

3. Dilillo D, Mauri S, Mantegazza C, Fabiano V, Mameli C, Zuccotti GV. Suicide in pediatrics: epidemiology, risk factors, warning signs and the role of the 
pediatrician in detecting them. Ital J Pediatr. 2015;41:49. https://www.ncbi.nlm.nih.gov/pmc/ articles/PMC4494780/

4. American Academy of Pediatrics, Committee on Adolescence. Suicide and Suicide Attempts in Adolescents. Pediatrics 2000; 105(4):871-4. http://pediatrics.aappublications.org/content/ pediatrics/105/4/871.full.pdf

5. Pelkonen $M$, Marttunen $M$. Child and adolescent suicide: Epidemiology, risk factors, and approaches to prevention, Pediatric Drugs 2003;5(4):243-65.

6. World health organization, Maternal, newborn, child and adolescent health, Adolescent health epidemiology, 2017 Available at: http://www.who. int/maternal_child_adolescent/epidemiology/ adolescence/en/

7. Cash SJ, Bridge JA. Epidemiology of Youth Suicide and Suicidal Behavior, Curr Opin Pediatr. 2009;21(5):613-19.

8. Bridge JA, Goldstein TR, Brent DA. Adolescent suicide and suicidal behavior. J Child Psychol Psychiatry 2006;47(3/4):372-94.

9. Shaw D, Fernandes JR, Rao C. Suicide in children and adolescents: a 10-year retrospective review. Am J Forensic Med Pathol. 2005;26(4):309-15.
10. Hepp U, Stulz N, Unger-Köppel J, Ajdacic-Gross V. Methods of suicide used by children and adolescents. Eur Child Adolesc Psychiatry. 2012;21(2):67-73.

11. American Psychiatric Association (APA), Diagnostic and Statistical Manual of Mental Disorders, Fifth Edition (DSM-5). 2013[Available at: https://www. psychiatry.org/psychiatrists/practice/dsm-5

12. Gunnell D, Bennewith O, Hawton K, Simkin S Kapur $\mathrm{N}$. The epidemiology and prevention of suicide by hanging: A systematic review. Intl J Epidem. 2005;34(2):433-42.

13. World health organization, $\mathbf{X} 70$ Intentional selfharm by hanging, strangulation and suffocation. ICD-10: 2007 version, Geneva. Available at: http://apps.who.int/classifications/apps/icd/ icd10online2007/

14. Salim A, Martin M, Sangthong B, Brown C, Rhee P, Demetriades $D$. Near-hanging injuries: A 10-year experience. Injury, Int J Care Injured, 2006;37:435-9.

15. DeMaso DR, Walter HJ, Wharff EA. Suicide and attempted suicide, In: Kliegman RM, Stanton BF, St Geme III JW, Schor NF, Behrman RE. Eds, Nelson Textbook of Pediatrics, 20 th edn, 2016;2(27):157-62. 